\title{
Problem-Based Service-Learning: Rewards and Challenges With Undergraduates
}

\section{Kenneth France}

Shippensburg University

Students in three Abnormal Psychology sections participated in problem-based service learning (PBSL). Desired learning outcomes included humanizing persons diagnosed with mental health disorders and more fully appreciating challenges experienced by such individuals. Students completing the PBSL projects evidenced decreased negative feelings and increased positive feelings toward consumers of mental health services. According to the community partners, students made valuable contributions to both the organizations and the mental health consumers served by those organizations. Students saw the activity as being challenging and rewarding.

A cademic service learning involves effore to enhance the quality of life A through collaborative endeavors among the professor, students, community organizations, and the targeted beneficiaries. It also enriches classroom-focused learning by providing real-life opportunities for students to use and think about academic content (Howard, 2001). Problem-based learning has students think through relevant issues, clarify aspects of the problem, locate and use relevant resources, investigate crucial principles, and incorporate appropriate concepts into their solutions (Duch, Groh, \& Allen, 2001). A melding of academic service learning and problem-based learning occurs in problem-based service learning (PBSL; Gordon, 2000). In addition to the characteristics of the two parent approaches, PBSL employs five fundamental components: specification of desired learning outcomes, collaboration with a community partner (typically a nonprofit organization) whose mission is directly related to the course 
content, implementation of real solutions to a broad problem posed by the community partner, enhancement of students' knowledge and skills, and frequent reflection and feedback among all involved parties.

Kezar (2002) asserted that professors should think holistically about learning outcomes and not limit students to narrowly defined cognitive development. Eyler and Giles (1999) discovered that some of the largest effects of service learning were associated with increased tolerance and enhanced citizenship skills. This study focuses on the development of such attributes, and apparently provides the first experimental evidence of PBSL-related change based on pre- and post-measures compared to a randomly assigned control group.

In my Abnormal Psychology sections, one of the goals is for students to humanize individuals who experience mental disorders. By that I mean seeing such persons as fellow human beings rather than as fearing-invoking, one-dimensional representations of mental illness. Another goal is for students to more fully appreciate the numerous challenges experienced by those who have serious mental disorders. The possibility of making greater progress toward these goals led me to try PBSL. I was intrigued by its potential to engage students and community members in joint efforts to solve real problems.

During the 2001-2002 academic year, for the first time in my teaching, I employed PBSL with one of my two Abnormal Psychology sections in the fall and with both sections in the spring. I did not provide advance notification to the fall students that PBSL would be part of one course so that the traditional section could serve as a control group. None of the sections were listed as a PBSL course. Each section met at a midday time on Mondays, Wednesdays, and Fridays for 50 minutes.

\section{METHOD}

\section{Participants}

There were three PBSL sections and one non-PBSL section. At the end of the term, the final enrollments for the four sections were fall section $A, 30$; fall section B, 27 (non-PBSL); spring section C, 30; and spring section D, 29. The withdrawals by students who attended at least one class were, respectively 1,1 , 5 , and 1 . The numbers of students who provided pre- and post-measures of feclings were $30,26,25$, and 29 , respectively.

\section{Procedure}

Prior to the start of the semesters, I sought a community partner for each PBSL class. That process took up to three months. The partner I used both 
semesters (sections $A$ and $D$ ) was a mental health association serving three counties. The organization's mission includes promoting mental health, advocating for mental health consumers and their families, encouraging understanding and acceptance among the general public with regard to challenges experienced by individuals with mental illness, spurring social action in support of adequate mental health services, and eliminating the stigma associated with mental illness. The partner for section $\mathrm{C}$ was a nonprofit corporation operating in two counties. That program serves adults with serious and persistent mental disorders by providing group homes, supervised apartments, and a drop-in center.

Eventually, a representative of the nonprofit organization wrote a letter (based on a draft I provided) inviting participation by the class in addressing a perceived problem. For the partner used both semesters, the letrer stated that the problem was to "develop ways for [mental health] consumers to be more active advocates." For the spring-only partner, the problem was to create "strategies for our consumers to improve their ability to live and function in the community, which includes developing and using natural support systems." The letter included a timeline that noted when the representative would visit the class early in the semester (week three) and dates for the following: deadline for proposals (week five), date for return of the proposals with her feedback (week six), deadline for final reports (week 12), and date for feedback from her on the completed projects and final reports (last week of class).

During both the implementation and proposal development phases, I required students to meet face-to-face with consumers. Activities included socializing, seeking input, and requesting feedback. The proposal developed with consumers had to include the following elements: identification of a specific problem and provision of relevant background information, goals and detailed plans that were realistic, clear explanations of how consumers and group members were going to interact, and a concrete description of how the project was going to have an impact on the problem identified by the community partner.

The course syllabus described desired learning outcomes associared with the PBSL sections. Two of the goals were humanizing persons who have mental health diagnoses and more fully appreciating challenges facing such individuals. Students addressed those issues in their final reports. Pre- and postmeasures of the students' feelings toward persons with serious mental disorders provided additional data relevant to the learning goals. 
On the morning of the first class day for the two sections of the course in the fall, I flipped a coin to determine which section would participate in PBSL. During the first class period in all four sections and prior to passing out the syllabus, I gave each student a form with the following instructions.

Imagine that in a few minutes from now you are going to have oneto-one conversations with some individuals who have serious mental disorders. How would you feel about interacting with individuals who have serious mental disorders? Check all that apply: hesitant, confident, scared, eager, apprehensive, composed, nervous, enthusiastic, anxious, comfortable, doubtful, interested, reluctant, willing.

There were seven positive feeling words and seven negative feeling words. I used the number of adjectives checked to generate positive and negative scorebased descriptors, with a maximum score of 7 and a minimum score of 0 .

On the first day of class, I provided each PBSL student with the community partner's letter and a syllabus that described the goals and activities of their community project learning experience. On the second day of the traditional class, I formed out-of-class groups (created according to when students said they were free to meet) of about four students each in which team members would work to produce two case studies; took pictures of the groups, which helps me to learn the students' names and, by putting a large label on the back of each photo, provides a space to record the groups' out-of-class meetings with me); and participated in "interview the professor," in which small groups generated and asked questions relating to the course, the discipline, and me. The PBSL sections engaged in the same activities (their out-ofclass groups would produce projects rather than case studies) along with some additional tasks. The teams developed ideas about what effective collaboration looks like and sounds like. I compiled the information and provided it to them in a handout at the next class meeting. On the third day of class, the PBSL groups developed quality criteria for the form, content, process, and impact of the proposal, implementation, and final report. I added my thoughts and developed a composite quality criteria handout for the entire class to use, which I distributed at the next class meeting. (Examples of quality criteria handouts are available upon request from the author.)

In week three, the community partner liaisons visited class for about 20 minutes, had the students sign confidentiality statements, and responded to questions. Both the community liaisons and 1 strongly encouraged the students to begin visiting consumers. I stated that I would not accept any proposal that was based solely on student ideas without consumer input. 
Students working in small groups accomplished all of the PBSL components. There were no individual PBSL requirements in addition to the group project, which counted as one of four equally weighted components of the course (the others being two exams, and the average of 11 quizzes).

Seaman (2000) noted that one sure way to sink a PBSL effort is to pile on a project requirement to a course that is already full. Compared to the traditional version of the course, I made the following additional adjustments. During the tenth and 11 th weeks of the course, the class did not meet for five 50-minute periods in order for students to have additional time to implement their projects, and we covered 11 rather than 13 chapters in the text.

Students produced a variety of projects (see Table 15.1 for a sample). The first three projects in the table addressed the goal of helping consumers become more effective advocares. The focus was on providing ways for consumers to communicate their message to encourage understanding and acceptance of challenges faced by persons with mental disorders and to decrease the stigma associated with mental illness. The last two projects in the table sought to help consumers live and function in the community.

TABLE. 15.1

\section{Student Projects}

Title Description

Informing the public about Wrote an article for the campus newspaper; mood disorders produced a campus symposium

Educating children about Prepared information about mental disorders mental disorders and presented it to a second-grade class

Addressing the communication Published a brochure and distributed it to law gap between mental health enforcement and mental health organizations patients and police officers

Educating consumers on Produced a notebook with chaprers on financial skills establishing good credit, balancing a checkbook, maintaining a budget, buying/renting a house, and buying a car

Promoting responsibility and Gave plants to consumers and helped them sense of worth learn plant-care skills

Team members sought consumer input regarding needs, thoughts about how to meer those needs, opinions of possibilities the students might pursue, 
contributions and reactions to specific student endeavors, and opinions of completed projects. Some students continued working with consumers after the semester was over. Students spent from two to more than ten hours with consumers, working with one to more than ten individuals. Typically, students spent 15 to 25 hours on the project. Most of the groups contacted the community partner representatives during both the proposal development phase, that involved the creation of a project plan, and the implementation phase, in which the students carried out the plan. (One-third of the project grade was based on the proposal and two-thirds on the implementation and final report.)

On the day in which the PBSL classes turned in their final reports, students completed the same survey form they had completed on the first day of class. For the spring sections, I also asked the students to rate how they actually felt during their first meeting with consumers.

\section{Results}

\section{Feelings Toward Consumers}

I conducted a MANOVA on the feeling words scores from the survey, with Positive and Negative as the two dependent variables; Time was a within subjects factor, and Section was a between subjects factor. This analysis, in which I used the Wilks' Lambda statistic, showed Time to be significant, $P(2,105)=$ $31.64, p<.001$ and also indicated a marginal interaction between Time and Section, $F(6,212)=2.14, p=.05$. I also conducted mixed $2 \times 4$ ANOVAs on the positive feeling words scores and on the negative feeling words scores, again with Time as a within subjects factor and Section as a between subjects factor. The results revealed a significant Time by Section interaction for the positive descriptors, $F(3,106)=3.28, p=.024$, but not for the negative descriptors. I followed that analysis with several univariate tests for each of the two types of scores. The means and standard deviations are shown in Table 15.2. There were no significant differences among the pre-test frequencies for the positive and negative feeling words or among post-test frequencies for the negative feeling words. There were, however, significant differences between the post-test frequencies for the positive descriptors. Because, in post hoc tests, there were no significant differences among the three PBSL sections on the positive descriptors, I combined these sections and contrasted them with the control section. The linear contrast between the control section $(M=3.42, S D$ $=1.94)$ and the three P'BSL sections combined $(M=4.49, S D=1.59)$ was significant, $F(1,106)=7.03, p<.01$. I also conducted mixed $2 \times 4$ ANOVAs on the positive feeling words scores and on the negative fecling words scores, 
again with Time as a within subjects factor and Section as a between subjects factor. The results revealed a significant Time by Section interaction for the positive descriptors, $F(3,106)=3.28, p=.024$, but not for the negative descriptors. Paired samples tests on the combined PBSL sections showed significantly more positive feeling words at the end of the semester $(M=4.49, S D=$ 1.59) than at the start of the term $(M=3.00, S D=1.71), t(83)=-8.32, p<$ .001 . A similar comparison of positive feeling words from students in the nonPBSL section did not reveal a significant difference between the pre-test positive feeling words $(M=3.00, S D=1.85)$ and the post-test positive feeling words $(M=3.42, S D=1.94), t(25)=-1.34, p>.05$.

TABlE 15.2

Means and Standard Deviations of Positive and Negative Feeling Words Reported by Non-PBSL and PBSL Students at the Beginning and End of the Semester

\begin{tabular}{lcccccccc}
\hline & \multicolumn{3}{c}{ Positive Feeling Words } & \multicolumn{3}{c}{ Negative Feeling Words } \\
& Non-PBSL & \multicolumn{2}{c}{ PBSL } & \multicolumn{3}{c}{ Non-PBSL } & \multicolumn{2}{c}{ PBSL } \\
\cline { 2 - 9 } & $\mathbf{M}$ & SD & M & SD & M & SD & M & SD \\
\hline Pre-test & 3.00 & 1.85 & 3.00 & 1.71 & 1.69 & 1.59 & 1.62 & 1.38 \\
Post-test & 3.42 & 1.94 & 4.49 & 1.59 & 1.46 & 1.42 & 1.00 & 1.14 \\
\hline
\end{tabular}

For the next set of comparisons, I set the significance level at .01 to adjust for multiple tests. Because there were no significant differences between two spring PBSL sections' score-based positive descriptors or between their scorebased negative descriptors, I combined the positive feelings scores for the two sections, as well as the negative feelings scores. The means and standard deviations are shown in Table 15.3. For the positive feeling words, paired samples tests showed nonsignificantly fewer positive feeling words for the actual first meeting $(M=2.43, \mathrm{SD}=1.73)$ than for the pre-test $(M=3.04, S D=1.80)$, $t(53)=2.20, p=.03$, and significantly more positive feeling words for the post-test $(M=4.67, S D=1.48)$ than for the actual first meeting $(M=2.43$, $S D=1.73), t(53)=-8.61, p<.001$. For the negative feeling words, paired samples tests showed significantly more negative feeling words for the actual first meeting $(M=2.76, S D=1.48)$ than for the pre-test $(M=1.74, S D=$ 1.38), $f(53)=-4.80, p<.001$, and significantly fewer negative feeling words for the post-test $(M=.96, S D=1.16)$, than for the actual first meeting $(M=$ $2.76, S D=1.48), t(53)=7.31, p<.001$. 
TABLE 15.3

Means and Standard Deviations of Positive and Negative Feeling Words Reported by Spring PBSL Students at the Beginning of the Semester, for Their First Visit With Consumers, and at the End of the Semester

\begin{tabular}{lcccc}
\hline & \multicolumn{2}{c}{ Positive Feeling Words } & \multicolumn{2}{c}{ Negative Feeling Words } \\
\cline { 2 - 5 } & $\mathbf{M}$ & SD & M & SD \\
\hline Pre-test & 3.04 & 1.80 & 1.74 & 1.38 \\
First Meeting & 2.43 & 1.73 & 2.76 & 1.48 \\
Post-test & 4.67 & 1.48 & .96 & 1.16 \\
\hline
\end{tabular}

The data showed that at the end of the course, students in the PBSL sections endorsed significantly more positive feeling words than did members of the control section. The PBSL students also reported significantly more positive feelings toward consumers than at the beginning of the semester, whereas the non-PBSL students did not show a significant increase. Another finding was that at the beginning of the spring semester the PBSL students underestimated their negative feelings. (They eventually chose more negative feelings to describe their actual first meeting with consumers.) Of greatest importance, though, is that at the end of the semester the reported negative feelings toward consumers (.96) were $65 \%$ lower than for the actual first meeting (2.76), and the reported positive feelings toward consumers (4.67) were $92 \%$ higher than for the actual first meeting (2.43).

\section{Student Ratings of the Courses}

For student ratings of the courses, the number of students who completed evaluations (ratings and anonymous comments) for sections A, B, C, and D were: 28, 22 (non-PBSL), 27, and 26. On a 6-point scale ranging from strongly disagree (1) to strongly agree (G), the student ratings for judging the professor to be effective in teaching the course were 5.8 for the control group (section B), 5.4 for the fall PBSL students (section A), 5.6 for section $C$ in the spring, and 5.7 for section $D$ in the spring.

\section{Students' Use of Office Hours}

For several years I have been employing out-of-class writing groups in which students collaborate on projects, such as case studies, and write group papers. I strongly encourage the groups to meet with me several times so I can give them feedback on their efforts prior to the date the final version is due. In the 
fall semester, the control class groups met with me an average of meeting with me 5.4 times to discuss their case studies. The PBSL groups met with me an average of 6.9 times (2.7 times to discuss the proposal, 1.7 times during implementation, and 2.5 times to discuss the final report).

\section{Student Comments on Two Learning Goals}

In their final reports, students addressed the learning goal of humanizing persons who have mental health diagnoses and evidenced in their writing that they more fully appreciated challenges faced by such individuals. The following comments are typical of what students wrote.

We learned that people who have disabilities are truly unique individuals who want the same things in life that most of us take for granted, such as maintaining a job, meeting responsibilities, and feeling proud of one's work.... Through doing something positive to improve the opportunities of the mentally handicapped individuals of our community, we understood that we could become involved in our society and evoke change.

\section{Anonymous Student Remarks About the Course}

At the end of the semester students anonymously responded to open-ended probes about the course. Of the 81 PBSL students (91\% of those registered) present for those evaluations, 56 (69\%) of them had PBSL-related comments that I interpreted to be positive, such as these two.

The most positive aspect was our problem-based project because we had to deal with relevant issues and we got to work with real people. It was the most beneficial experience I have had in college so far.

I am glad we had the opportunity to do the outreach program. If I had been given a choice about doing it, I probably would not have chosen to do it, but I'm glad I did it. It was one of the best learning opportunities I had in college. I had a good time doing it and I learned a lot. The most frustrating part was coming up with an idea, but in real life you will also be faced with frustrating circumstances.

Two students (2\%) complained that the project took too much time, which I interpreted as being negative comments. Seven students (9\%) made comments in the vein of the following remark, "The beginning is too vague 
and, having never done anything like it before, made it difficult to get started. I liked the project once it got started and thought it was a good idea."

\section{Comments by Representatives of the Community Partners}

Representatives of the community partners expressed their appreciation for being involved in the classes. Both community partners expressed the opinion that consumers had been helped by the projects and asked to continue their association with the course during the next semester.

\section{Discussion}

Non-PBSL students did not significantly change their reported positive or negative feelings toward persons diagnosed as having serious mental disorders. Compared to the non-PBSL students, the PBSL participants reported significantly more positive feelings at the end of the semester. When compared to reports of how they felt during their actual first meetings with consumers, at the end of the semester the spring PBSL students listed significantly more positive feelings and significantly fewer negative feelings. The PBSL students also helped consumers, gave needed assistance to the community partners, and provided beneficial information to a variety of other groups.

Students in the three sections experienced all of the previously identified characteristics of PBSL. The students, community organizations, consumers, and professor engaged in collaborative efforts intended to enhance consumers' quality of life. Students applied academic content (e.g., their course-based knowledge regarding challenges associated with various mental disorders) to real-life situations. Team members considered relevant issues (e.g., what content knowledge to apply), clarified aspects of the problem (e.g., what was a realistic issue for them to address), then identified and used appropriate resources (e.g., the knowledge and talents of the consumers themselves) and concepts (e.g., diagnostic and treatment information). The syllabus described learning outcomes (including humanizing consumers and more fully appreciating challenges they face) in which students demonstrated progress through their comments and reported feelings. The community partners engaged in activities directly relevant to the course (one was a mental health association and the other was a nonprofit corporation serving persons diagnosed with serious mental disorders). The partners posed broadly defined problems. Students learned information (e.g., the effects of medications) that they then saw as being relevant in their problem-solving projects. Throughout the course, the students, consumers, community partners, and professor freely exchanged feedback. 
As noted earlier, about one student in ten thought they should have been told more specifically what to do. As I discussed with the classes several times, though, one of the crucial aspects of PBSL is to provide a problem that is purposely broad in order to allow for creativity on the part of the students. Specifically telling students what to do would deprive them of a valuable learning opportunity.

The two most common difficulties mentioned by students were time management and the vagaries of working with real programs and real people in the community. Both were challenges that all of the groups eventually confronted and resolved in productive ways.

When teaching the course during the 2002-2003 academic year, I moved the community partner visit to the second day of class, so that students would have more time to interact with consumers during the proposal development phase. Another adjustment came from an idea described by Weimer (2002). I had each group select one or two group liaisons whom I hosted for lunch every other Friday. (One Friday I met with representatives from the first section and the next Friday I met with representatives from the second section.) While enjoying a pizza and some soda, we discussed how the groups were functioning, progress they were making, and challenges they were facing. In addition to being interested in information from other groups, the representatives said they appreciated feedback from students and me on their group's efforts.

In each PBSL section, I had one or two groups complain to me about the lack of effort by some members. The group's agreed-upon descriptions of effective collaboration provided an excellent resource for reaffirming the performance standards expected within the group. The grade assigned for the project was a maximum grade. If the team members agreed that everyone had done what was expected of them, then the team decided that everyone should receive the maximum grade. Some groups decided that not everyone had fulfilled their responsibilities, and those persons received lower grades as agreed upon in consultation between the group and me.

PBSL presents certain challenges for all involved. Although recognizing there may be some struggle along the way, the consensus opinion among the students, community partners, participating consumers, and myself is that the resulting learning and service are well worth the effort.

\section{ACKNOWLEDGMENTS}

The author wishes to thank Adrian Tomer, Diane Clark, and Angela Bartoli for their consultation during preparation of the manuscript. 


\section{REFERENCES}

Duch, B. J., Groh, S. E., \& Allen, D. E. (2001). Why problem-based learning? A case study of institutional change in undergraduate education. In B. J. Duch, S. E. Groh, \& D. E. Allen (Eds.), The power of problem-based learning (pp. 3-11). Sterling, VA: Stylus.

Eyler, J., \& Giles, D. E., Jr. (1999). Where's the learning in service-learning? San Francisco, CA: Jossey-Bass.

Gordon, R. (2000). Problem based service learning: The power of learning through service. In R. Gordon (Ed.), Problem based service learning: A fieldguide for making a difference in higher education (2nd ed., pp. 1-13). Keene, NH: Education by Design.

Howard, J. (2001). Michigan Journal of Community Service Learning: Service-learning course design workbook. Ann Arbor, MI: OCSL Press, The University of Michigan.

Kezar, A. (2002). Assessing community service learning: Are we identifying the right outcomes? About Campus, 7, 14-20.

Seaman, R. (2000). Project design. In R. Gordon (Ed.), Problem based servicelearning: A fieldguide for making a difference in higher education (2nd ed., pp. 15-23). Keene, NH: Education by Design.

Weimer, M. (2002). Learner-centered teaching: Five key changes to practice. San Francisco, CA: Jossey-Bass.

\section{Contact:}

Kenneth France

Department of Psychology

Shippensburg University

Shippensburg, PA 17257

Voice (717) 477-1108

Fax (717) $241-2534$

Email franceassoc@earthlink.net .

Kenneth France is Professor of Psychology at Shippensburg University and is the Coordinator of the Summer Academy for the Advancement of College Teaching, as well as the Annual Conference for the Advancement of College Teaching and Learning (both sponsored by the Pennsylvania State System of Higher Education). He serves as Editor of the Psi High Newsletter, a publication for high school psychology teachers in Pennsylvania, and he is the lead trainer for a network of suicide prevention trainers in Pennsylvania. He practices clinical psychology at Franco Psychological Associates in Carlisle, Pennsylvania, and he is the lead mentor for New Hope Online, an Internetbased crisis intervention service. 